\title{
Perfil nutricional de moradores de rua e caracterização da alimentação distribuída em albergues do município de São Paulo
}

\author{
Maria Sinedes Neres dos Santos ${ }^{1}$, Claudio Oliveira Montenegro Pita, \\ Shyrle Mendes Trabuco Soares ${ }^{1}$, Vivian Lee ${ }^{1}$, \\ Hellen Daniela Coelho ${ }^{2}$, Eliana Menegon Zaccarelli ${ }^{3}$
}

\begin{abstract}
A população de rua sobrevive no que se refere à alimentação, basicamente por meio da ação filantrópica de organizações sociais. Este trabalho teve por objetivo avaliar o estado nutricional de frequentadores de albergues do município de São Paulo, bem como caracterizar a alimentação oferecida nos mesmos, no que se refere à composição dos cardápios e a aspectos sensoriais. A pesquisa foi realizada em 3 albergues, com 200 indivíduos do gênero masculino durante o mês de julho de 2009. Peso e altura foram aferidos para cálculo do Índice de Massa Corporal (IMC), classificado segundo critérios da Organização Mundial da Saúde - OMS (2003). A análise sensorial foi feita para avaliar sabor, variedade e aceitação global da alimentação ofertada, com utilização da Escala Hedônica Facial de cinco pontos. Os resultados indicaram a prevalência de $25 \%$ dos indivíduos com sobrepeso e 11,5\% de obesos. No que se refere à análise sensorial, as proporções de entrevistados que classificaram as refeições nas categorias "Bom" ou "Ótimo" foram de: 68 a 90\%, quando foi avaliado o sabor; 58 a $82 \%$ em relação à variedade; e 64 a $94 \%$ quanto à aceitação global. $O$ albergue que contava com melhor infraestrutura e equipe de nutricionistas não obteve a melhor avaliação quanto aos aspectos sensoriais da alimentação distribuída. São necessários estudos que identifiquem os determinantes da aceitação das refeições distribuídas nos albergues.
\end{abstract}

Palavras-chave: abrigo, estado nutricional, análise sensorial.

\section{Nutritional profile of the homeless and characterization of food distributed in hostels in the city of São Paulo}

The homeless population survives with regard to nutrition, primarily through the philanthropy of social organizations. This study evaluates the nutritional status of hostels users in São Paulo and characterizes the food served in them, with regard to composition and sensory aspects of the menus available. The survey was conducted in three shelters, fostering 200 male individuals during the month of July 2009. Weight and height were measured to calculate the body mass index (BMI), classified according to criteria of the World Health Organization - WHO (2003). Sensory analysis was performed to evaluate flavor, variety and overall acceptability of foods offered, using the facial hedonic scale of five points. The results indicated a prevalence of $25 \%$ of overweight individuals and $11.5 \%$ obese. With regard to sensory analysis, the proportions of respondents who rated their meals as "Good" or "excellent" were 68 to $90 \%$ for flavor, 58 to $82 \%$ with respect to variety; and from 64 to 94\%, for overall acceptance. The hostel we had better infrastructure and team of nutritionists did not

\footnotetext{
${ }^{1}$ Nutricionista pela Universidade Paulista (UNIP), São Paulo, SP.

${ }^{2}$ Docente do Curso de Graduação em Nutrição, Universidade Paulista (UNIP), São Paulo, SP.

${ }^{3}$ Docente do Curso de Graduação em Nutrição, Universidade Paulista (UNIP), São Paulo, SP.

Correspondência: Rua Dardanelos, 108, Apto. 102, Bloco B, Alto da Lapa, CEP 05468-010, São Paulo, SP. E-mail: elianamzac@gmail.com
} 
get the best rate the sensory aspects of food distributed. Research is needed to identify the determinants of acceptance of meals distributed in the hostels.

Key-words: refuge, nutritional status, sensory analysis.

\section{INTRODUÇÃO}

Segundo o dicionário Aurélio "albergue" significa lugar onde se recolhe alguém por caridade, pousada ou estalagem onde eram recolhidos peregrinos e viajantes, principalmente os pobres.

Partindo do ponto de vista de Dias [1] algumas populações que se encontram na rua, ao apropriar-se dos espaços públicos, usam de estratégias próprias de sobrevivência, sendo que a principal delas é recorrer às chamadas "bocas de rango", locais de distribuição gratuita de comida, feita predominantemente em espaços públicos (praças, parques e viadutos), por instituições filantrópicas de caráter social. A escolha por determinado local para realização das refeições depende de fatores, tais como: o modo como os indivíduos organizam seu cotidiano; a dinâmica de funcionamento dos pontos de distribuição da alimentação; e a qualidade e a variedade da alimentação oferecida.

A população de rua sobrevive no que se refere à alimentação, basicamente por meio da ação filantrópica exercida pelas organizações sociais de caráter privado, cunhada pela caridade religiosa. A existência de instituições de assistência social é uma das peculiaridades da civilização cristã: a trajetória das instituições sociais não é monolítica; elas sofreram algumas transformações nos diferentes períodos históricos, diversificando suas práticas, modernizando suas estruturas burocráticas, incorporando novos conhecimentos produzidos na sociedade. O campo da filantropia opera de maneira diversificada, não se restringindo à distribuição da comida, mas ajudando tanto a indivíduos como famílias pobres, fornecendolhes outros auxílios, como roupas, calçados, remédios e cestas básicas. $\mathrm{O}$ trabalho dessas organizações junto à pobreza assume um sentido de dupla ação, ora na consecução de seus princípios doutrinários, ora na perspectiva de uma ação social. $\mathrm{O}$ ato da distribuição da comida é permeado por profundo sentimento religioso, movido pela comiseração para com o semelhante [2].

Glasser [3] faz uma distinção nítida para as causas da existência da população sem-teto, nos países industrializados e naqueles em desenvolvimento. Nos primeiros, a autora postula que o problema está relacionado com o déficit habitacional, principalmente

o relativo às moradias de baixa renda, associado com a desestruturação familiar, o abuso do álcool e das drogas e a desinstitucionalização de pacientes psiquiátricos. Nos países em desenvolvimento, a explicação está centrada, segundo a autora, na migração da população rural para os centros urbanos, nos altos índices de desemprego e subemprego, e na existência de um grande número de refugiados e de vítimas de catástrofes.

No Brasil, os sem-teto são tradicionalmente representados por migrantes que se deslocam em busca de emprego. Há que se especificar que fenômenos migratórios podem estar contribuindo diretamente para o aumento da população de rua, tendo em vista, também, que esses fenômenos vêm se modificando ao longo do tempo. Rosa, já em $1995^{[4]}$, destacou que, além disso, as novas propostas de sistemas econômicos geradas pelos governos neoliberais, também alteraram profundamente a organização do trabalho, sem ter dimensionado como isto vinha ocorrendo em relação à população de rua.

De modo geral, pode-se afirmar que alguns setores dos países desenvolvidos estão cônscios de que um segmento populacional é excluído da sociedade afluente, para o qual procuram dar a assistência minimamente necessária. Já nos países em desenvolvimento, é pequena a conscientização acerca do problema e existem poucas pesquisas. Com efeito, o que se faz é improvisar alguns albergues que ficam muito aquém das necessidades [5].

Na cidade de São Paulo, o decreto no 40.232, de 2 de janeiro de 2001, que regulamenta a Lei no 12.316, de 16 de abril de 1997, obriga o Poder Público Municipal a prestar atendimento à população de rua da cidade, e dá outras providências. Entre as obrigações está a de fornecer uma alimentação com adequado padrão de nutrição, que apresente boa qualidade, de modo a atender às necessidades calóricas de cada morador, sob supervisão de nutricionistas [ $[$ ].

Não sobram dúvidas de que a distribuição da alimentação nos albergues deve seguir os preceitos da 
segurança alimentar e nutricional, cujo conceito, ainda em construção no Brasil, inclui simultaneamente, a dimensão nutricional, a disponibilidade (food security) e a segurança do alimento (food safety). "Segurança Alimentar e Nutricional (SAN) é a realização do direito de todos ao acesso regular e permanente a alimentos de qualidade, em quantidade suficiente, sem comprometer o acesso a outras necessidades essenciais, tendo como base práticas alimentares promotoras de saúde, que respeitem a diversidade cultural e que sejam social, econômica e ambientalmente sustentáveis" " 7$]$.

Mais recentemente, a noção de segurança alimentar e nutricional vem sendo considerada como um objetivo de política pública. A III Conferência de SAN, realizada, em 2007, em Fortaleza, definiu SAN "como objetivo estratégico para o desenvolvimento com abrangência intersetorial, que se orienta pelos princípios do Direito Humano à Alimentação Adequada e Saudável (DHAA) e da Soberania Alimentar" ${ }^{[8] .}$

Para o setor de Saúde Pública brasileiro é importante lembrar as possibilidades e dificuldades da pesquisa com os abrigados. O estudo dessa temática deve ser incrementado, constituindo mais um esforço na tarefa de minimização do problema, conjugado aos que atualmente são efetivados por outros setores, principalmente aqueles inerentes à assistência social. Nesse sentido o objetivo desse trabalho foi caracterizar a alimentação oferecida e sua aceitação pelos frequentadores de albergues do município de São Paulo e avaliar o estado nutricional dos mesmos.

\section{METODOLOGIA}

A presente pesquisa caracteriza-se como um estudo de caso, com natureza exploratória/descritiva, realizado com indivíduos em situação de rua que frequentam albergues no município de São Paulo.

Foram analisados três albergues: no albergue 1 foram entrevistadas 100 pessoas, e nos albergues 2 e 3 , 50 indivíduos cada. As instituições pesquisadas e o número de entrevistados foram determinados por conveniência. Os dados foram coletados durante o mês de julho de 2009.

\section{Caracterização das instituições}

Albergue 1 : está localizado na zona leste de São Paulo, cujo funcionamento teve início em 1996. Em julho de 2009 acolhia 1.115 indivíduos do gênero masculino. Durante esses 13 anos de funcionamento chegou a hospedar 30.000 pessoas e produziu e forneceu mais de 10 milhões de refeições. A casa possui 1.500 leitos e funciona das 7:00 às 21:00 horas. É um projeto do Serviço Missionário Jovem (Sermig), com sede em Turim (Itália) e conta com um convênio da Secretaria de Assistência e Desenvolvimento Social do Estado de São Paulo e doações da comunidade. A instituição conta com 3 nutricionistas, um quadro de 70 funcionários e a ajuda de 100 voluntários de diversas áreas. Conta, também, com infraestrutura adequada para o preparo de refeições em larga escala. Possui parceria com algumas instituições, como o Centro de Apoio ao Trabalhador (CEAT), que realiza atendimento às pessoas desempregadas, por meio de cadastramento, levantamento de perfil profissional, cursos de capacitação e inserção no mercado de trabalho; o programa "Acessa São Paulo", que tem como objetivo realizar a inclusão digital dos mais carentes; a Secretaria Estadual de Assistência e Desenvolvimento Social (SEADS), que manteve convênio com a casa de acolhida durante 12 anos (de 1996 a 2008); a Universidade Anhembi Morumbi, que realizou cursos e palestras em diversas áreas; o SENAI (Serviço Nacional de Aprendizagem Industrial) que também implementou cursos voltados para a capacitação profissional; além de contar com vários colaboradores, como o Serviço Brasileiro de Apoio às Micro e Pequenas Empresas (SEBRAE) e a Federação das Indústrias do Estado de São Paulo (FIESP).

Albergue 2 : está localizado na zona oeste de São Paulo. Começou a funcionar em 2004, com atendimento integral (24 horas por dia) e capacidade de 90 leitos. Atualmente vem acolhendo aproximadamente 85 indivíduos do gênero masculino, com faixa etária de 18 a 80 anos. A instituição possui equipe terapêutica de reabilitação (médicos e agentes de saúde, assistente social, psicólogos e enfermeiros). Tem o apoio da prefeitura de São Paulo, e recebe doações da Companhia de Entrepostos e Armazéns Gerais de São Paulo (CEAGESP), de varejões e de rede de hipermercados. Possui instalação semelhante a uma cozinha doméstica para o preparo de refeições e não conta com o profissional nutricionista no seu quadro de funcionários. A casa oferece aos acolhidos oficinas de recreação, artesanato e leitura.

Albergue 3 : é uma casa de convivência, localizada no centro de São Paulo, com funcionamento das 8:00 às 16:00 horas, para indivíduos de ambos os gêneros. O projeto teve início em 1994, sendo fruto de uma parceria entre o Pensamento Nacional das Bases Empresariais (PNBE) e a Organização de Auxilio 
Fraterno (OAF). Tem capacidade para receber 350 pessoas no espaço que foi cedido em comodato pela Prefeitura Municipal de São Paulo. A associação tem diversificado suas atividades e ampliado suas parcerias, como aquela mantida junto à Secretaria do Trabalho e ao Fórum das Organizações e da População de Rua, cuja finalidade é inserir os moradores de rua no mercado de trabalho. A instituição oferece treinamento de artesanato, além de disponibilizar cursos profissionalizantes, entre eles destacam-se os cursos de cozinha e alfabetização. Outros recursos da instituição são os serviços de higiene (banho, lavagem de roupas), alimentação, assistência à saúde e regularização de documentos. Oferece também atividades de desenvolvimento pessoal, educativas, culturais, esportivas e de lazer, trabalho em equipe e convivência em grupo, experiências de jardinagem com a utilização de adubo orgânico produzido na associação e outros projetos visando o bem-estar do acolhido. A produção de refeições é feita em espaço adaptado e com poucos equipamentos. A equipe da cozinha conta com um cozinheiro contratado e ajudantes da própria casa, não havendo na equipe o profissional nutricionista.

\section{Avaliação do estado nutricional}

Para a avaliação do estado nutricional foram aferidos peso e altura, com uma balança eletrônica da marca Filizola ${ }^{\circledR}$, com capacidade para $120 \mathrm{~kg}$ e uma fita métrica inelástica milimetrada. Os participantes foram pesados com camiseta, calça, descalços, em posição ortostática, com a massa do corpo distribuída nas duas pernas, braços ao longo do corpo, pés unidos, joelhos esticados e a cabeça orientada no plano horizontal de Frankfurt. A medida foi obtida em apnéia após uma inspiração profunda [?].

O estado nutricional foi calculado a partir destes dados, através do Índice de Massa Corporal (IMC) para adultos, proposto pela Organização Mundial da Saúde (OMS) [10], em $\mathrm{kg} / \mathrm{m}^{2}$. Para apresentação dos resultados, foram agrupadas as categorias (desnutrição grau I, II e III como "desnutrição", e obesidade grau I, II e III como "obesidade"). Nas análises envolvendo a associação entre estado nutricional e outras variáveis, como a idade, por exemplo, o estado nutricional foi expresso segundo a presença ou ausência de excesso de peso. Foi aplicado questionário para levantamento da idade e da presença de doenças referidas pelos participantes, com diagnóstico médico.

\section{Caracterização da composição dos cardápios das instituições}

Para caracterizar a alimentação oferecida nos albergues, cada instituição foi visitada por três dias consecutivos para observação das preparações oferecidas. Com exceção do albergue 1, os demais albergues não contavam com planejamento de cardápios. O número de dias de observação foi definido com base na disponibilidade das instituições em sediar a pesquisa. Os cardápios foram avaliados, na presente pesquisa, de forma qualitativa, comparando-se a participação dos grupos de alimentos nos cardápios ao preconizado pelo Guia alimentar para a população brasileira ${ }^{[1]}$.

\section{Caracterização de aspectos sensoriais da alimentação dos albergues}

Foram avaliados a aceitação global, o sabor e a variedade das refeições distribuídas nos albergues, empregando Escala Hedônica Facial de cinco pontos: 1 - Péssimo; 2 - Ruim; 3 - Indiferente; 4 - Bom; e 5 Ótimo. Neste questionário também foi perguntado ao participante o número de refeições que ele considerava necessário para que uma pessoa se mantivesse saudável.

\section{Aspectos éticos}

Os entrevistados participaram das entrevistas voluntariamente, não sendo obrigados a participar do estudo. Todos que participaram assinaram um Termo de Consentimento Livre Esclarecido. Este trabalho foi aprovado pelo Comitê de Ética em Pesquisa da Universidade Paulista (UNIP), com o número de protocolo 284/09.

\section{Análise de dados}

Foi criado um banco de dados no programa Microsoft Office Excel 2003 para tabulação das respostas obtidas nos questionários. A análise estatística envolveu testes de Qui-quadrado, utilizando-se o software Stata, versão 10 [12]. Adotou-se como nível de significância $p$ $<0,05$.

\section{RESULTADOS}

\section{Caracterização da população estudada - idade, estado nutricional e doenças}

A média de idade entre os frequentadores do albergue 1 foi de 39,9 anos $( \pm 11,5), 37,9$ ( \pm 10,8) para o albergue 2 e 46,1 ( \pm 9,6) entre os indivíduos do albergue 3.

Os dados mostram que a faixa etária de indivíduos em situação de rua variou conforme os 
albergues (Tabela 1). Houve predomínio daqueles com idade inferior a 39 anos nos albergues 1 e 2 , enquanto no terceiro, prevaleceu os maiores de 40 anos.

Com relação ao estado nutricional, os índices de sobrepeso e obesidade (excesso de peso) na população estudada somaram $36,5 \%$, enquanto o baixo peso representou apenas 3,5\% (Figura 1).
$O$ índice de indivíduos que apresentaram alguma doença foi de $25,5 \%$ sendo a mais frequente a hipertensão $(8 \%)$ seguida da hepatite $(2,5 \%)$ e gastrite $(2 \%)$. A dependência química (álcool e drogas) atingiu $1,5 \%$ dos indivíduos, conforme observado na Figura 2.

Tabela 1. Distribuição dos indivíduos segundo idade e albergue. São Paulo, 2009.

\begin{tabular}{lrrrrrr}
\hline & \multicolumn{7}{c}{ Albergues } \\
\cline { 2 - 7 } & \multicolumn{7}{c}{ Idade (anos) } & $n$ & $\%$ & $n$ & $\%$ & $n$ & $\%$ \\
\cline { 2 - 7 } & 34 & 34,0 & 15 & 30,0 & 1 & 2,0 \\
\hline$\leq 30$ & 23 & 23,0 & 12 & 24,0 & 16 & 32,0 \\
31 a 39 & 24 & 24,0 & 15 & 30,0 & 13 & 26,0 \\
40 a 49 & 19 & 19,0 & 8 & 16,0 & 20 & 40,0 \\
$\geq 50$ & 100 & 100,0 & 50 & 100,0 & 50 & 100,0 \\
\hline Total & & & & & & 3 \\
\hline
\end{tabular}

Nota: $p=0,01$.

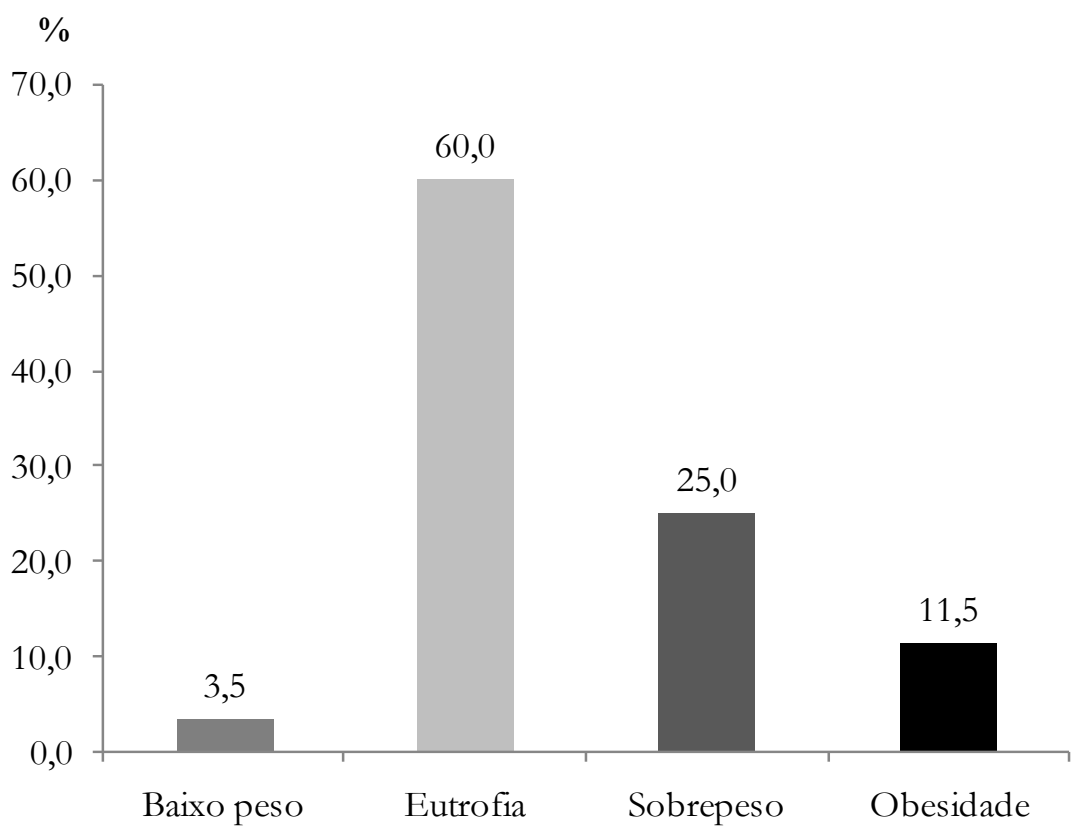

Figura 1. Distribuição percentual dos indivíduos segundo o estado nutricional. São Paulo, 2009.

Quando se analisou o estado nutricional em função da adesão aos albergues (Tabela 2), verificou-se que no albergue 1 foi encontrada a menor prevalência de excesso de peso $(27 \%)$. 
$\mathrm{Na}$ associação entre excesso de peso e idade dos indivíduos estudados, apresentada na Tabela 3, a análise estatística se mostrou no limite da significância. No entanto, nota-se uma tendência de aumento no índice de excesso de peso à medida que aumenta a idade.
Avaliando-se os dados da Tabela 4, nota-se que entre aqueles que acham que o ideal é ter 4 ou mais refeições por dia a prevalência de excesso de peso é menor. Da mesma forma, entre os indivíduos que consideram que o ideal é ter até 2 refeições ao dia foi observada maior proporção de excesso de peso.

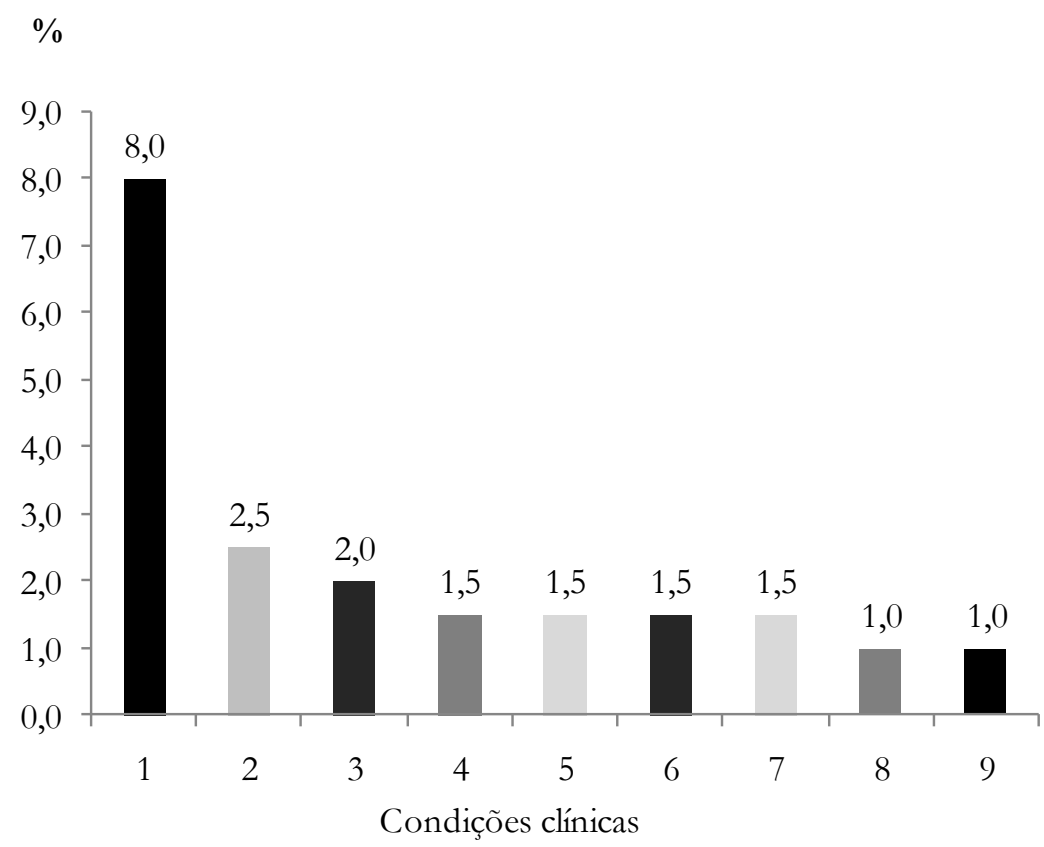

Figura 2. Percentual das condições clínicas referidas pelos participantes. São Paulo, 2009. Legenda: 1 - Hipertensão; 2 - Hepatite; 3 - Gastrite; 4 Bronquite; 5 - Epilepsia; 6 - Penumonia; 7 - Dependência química; 8 Colesterol; 9 - Deficiência visual.

Tabela 2. Distribuição dos indivíduos segundo estado nutricional e albergue. São Paulo, 2009.

\begin{tabular}{|c|c|c|c|c|c|c|}
\hline \multirow{3}{*}{ Excesso de peso } & \multicolumn{6}{|c|}{ Albergues } \\
\hline & \multicolumn{2}{|c|}{1} & \multicolumn{2}{|c|}{2} & \multicolumn{2}{|c|}{3} \\
\hline & $n$ & $\%$ & $n$ & $\%$ & $n$ & $\%$ \\
\hline $\operatorname{Sim}$ & 27 & 27,0 & 24 & 48,0 & 22 & 44,0 \\
\hline Não & 73 & 73,0 & 26 & 52,0 & 28 & 56,0 \\
\hline Total & 100 & 100,0 & 50 & 100,0 & 50 & 100,0 \\
\hline
\end{tabular}

Nota: $p=0,019$. 
Tabela 3. Distribuição dos indivíduos segundo estado nutricional e idade. São Paulo, 2009.

\begin{tabular}{|c|c|c|c|c|c|c|}
\hline \multirow{3}{*}{ Idade (anos) } & \multicolumn{6}{|c|}{ Excesso de peso } \\
\hline & \multicolumn{2}{|c|}{ Não } & \multicolumn{2}{|c|}{$\operatorname{Sim}$} & \multicolumn{2}{|c|}{ Total } \\
\hline & $n$ & $\%$ & $n$ & $\%$ & $n$ & $\%$ \\
\hline$\leq 30$ & 38 & 76,0 & 12 & 24,0 & 50 & 100,0 \\
\hline 31 a 39 & 35 & 68,6 & 16 & 31,4 & 51 & 100,0 \\
\hline 40 a 49 & 29 & 55,8 & 23 & 44,2 & 52 & 100,0 \\
\hline$\geq 50$ & 25 & 53,2 & 22 & 46,8 & 47 & 100,0 \\
\hline Total & 127 & 63,5 & 73 & 36,5 & 200 & 100,0 \\
\hline
\end{tabular}

Nota: $p=0,059$.

Tabela 4. Opinião dos participantes em relação ao número de refeições considerado ideal para a manutenção da saúde, segundo estado nutricional. São Paulo, 2009.

\begin{tabular}{|c|c|c|c|c|c|c|}
\hline \multirow{3}{*}{$\begin{array}{l}\text { Número de } \\
\text { refeições }\end{array}$} & \multicolumn{6}{|c|}{ Excesso de peso } \\
\hline & \multicolumn{2}{|c|}{ Não } & \multicolumn{2}{|c|}{ Sim } & \multicolumn{2}{|c|}{ Total } \\
\hline & $n$ & $\%$ & $n$ & $\%$ & $n$ & $\%$ \\
\hline$\leq 2$ & 29 & 53,7 & 25 & 46,3 & 54 & 100,0 \\
\hline 3 & 50 & 60,2 & 33 & 39,8 & 83 & 100,0 \\
\hline$\geq 4$ & 44 & 75,9 & 14 & 24,1 & 58 & 100,0 \\
\hline
\end{tabular}

Nota: $p=0,041$. Obs: 5 indivíduos (2,5\% da amostra total) não souberam opinar.

\section{Caracterização e composição qualitativa dos cardápios}

Foram analisados os cardápios ofertados pelas instituições por três dias consecutivos (Quadro).

Os albergues 1 e 3 apresentam o mesmo padrão de refeições: café da manhã, almoço e jantar. $\mathrm{O}$ café da manhã era composto por um alimento fonte de carboidratos e um alimento fonte de cálcio. $\mathrm{O}$ almoço era composto por um alimento fonte de carboidrato, uma opção de leguminosa, uma guarnição, uma opção de carne variando a cada dia, um tipo de salada e uma sobremesa. O jantar mantinha a mesma oferta do almoço ou eram oferecidas sopas ou pratos únicos (como macarronada).

No albergue 2 também eram oferecidas 3 refeições por dia, sendo elas: café da manhã, almoço e lanche da tarde. O café da manhã era composto de um alimento fonte de carboidratos e um alimento fonte de cálcio. No almoço havia oferta de um alimento fonte de carboidrato e uma opção de leguminosa. Em dois dias foi servida uma opção de carne, sendo que o dia em que não foi ofertado alimento fonte de proteína de origem animal ofereceu-se dois alimentos fontes de carboidratos (arroz e macarrão). Em um dia não houve oferta de salada. O lanche da tarde era composto apenas por um alimento fonte de carboidratos e suco artificial, não apresentando variação no decorrer dos 3 dias.

\section{Avaliação de aspectos sensoriais}

A Figura 3 mostra que em relação ao sabor da refeição as categorias "bom" e "ótimo" predominaram nos 3 albergues, sendo o maior percentual (90\%) registrado para as refeições distribuídas no albergue 3 . $\mathrm{O}$ albergue que apresentou maior rejeição em relação ao sabor foi o albergue 2 com um percentual de $18 \%$. 


\begin{tabular}{|c|c|c|}
\hline \multicolumn{3}{|c|}{ Albergue 1} \\
\hline Primeiro dia & Segundo dia & Terceiro dia \\
\hline Café da manhã & Café da manhã & Café da manhã \\
\hline Café com leite & Café com leite & Café com leite \\
\hline Pão caseiro com manteiga & Pão com manteiga & Pão com manteiga \\
\hline Almoço & Almoço & Almoço \\
\hline Arroz & Arroz & Arroz \\
\hline Feijão & Feijão & Feijão \\
\hline Abobrinha refogada & Frango cozido & Couve \\
\hline Carne com batata & Mandioquinha & Farofa \\
\hline Farinha & Salada (alface e tomate) & Salada (vinagrete e alface) \\
\hline Salada (acelga e tomate) & Leite fermentado & \\
\hline \multicolumn{3}{|l|}{ Laranja } \\
\hline Jantar & Jantar & Jantar \\
\hline Sopa de carne moída & Arroz & Macarronada \\
\hline Salada (alface e tomate) & Feijão & Salada (alface e tomate) \\
\hline Banana & Carne moída & Creme de morango \\
\hline & Salada (escarola e tomate) & \\
\hline & Gelatina & \\
\hline \multicolumn{3}{|c|}{ Albergue 2} \\
\hline Primeiro dia & Segundo dia & Terceiro dia \\
\hline Café da manhã & Café da manhã & Café da manhã \\
\hline Achocolatado & Café com leite & Café com leite \\
\hline Bolacha de água e sal & Pão com manteiga & Pão com manteiga \\
\hline Almoço & Almoço & Almoço \\
\hline Arroz & Arroz & Arroz \\
\hline Feijão & Feijão & Feijão \\
\hline Carne moída com batata & Macarronada & Frango assado \\
\hline Salada (acelga e tomate) & Salada (alface e tomate) & Salada (alface e tomate) \\
\hline Lanche da tarde & Lanche da tarde & Lanche da tarde \\
\hline Suco & Suco & Suco \\
\hline Bolacha de água e sal & Bolacha de água e sal & Bolacha de água e sal \\
\hline \multicolumn{3}{|c|}{ Albergue 3} \\
\hline Primeiro dia & Segundo dia & Terceiro dia \\
\hline Café da manhã & Café da manhã & Café da manhã \\
\hline Café com leite & Café com leite & Café com leite \\
\hline Pão com manteiga & Pão com manteiga & Pão com manteiga \\
\hline Almoço & Almoço & Almoço \\
\hline Arroz & Arroz & Arroz \\
\hline Feijão & Feijão & Feijão \\
\hline Carne moída com salsicha & Farofa de cenoura & Carne com mandioca \\
\hline Salada (alface e tomate) & Omelete & Farofa \\
\hline \multirow[t]{2}{*}{ Mexerica } & Salada (alface e tomate) & Salada (vinagrete e alface) \\
\hline & Banana & Abacaxi \\
\hline Jantar & Jantar & Jantar \\
\hline Arroz & Sopa de legumes e carne moída & Macarronada \\
\hline Feijão & Gelatina & Salada (alface e cenoura) \\
\hline Frango cozido & & Creme de morango \\
\hline Purê de batata & & \\
\hline Salada (beterraba e escarola) & & \\
\hline
\end{tabular}

Quadro. Caracterização dos cardápios ofertados por três dias consecutivos em albergues do município de São Paulo, 2009. 


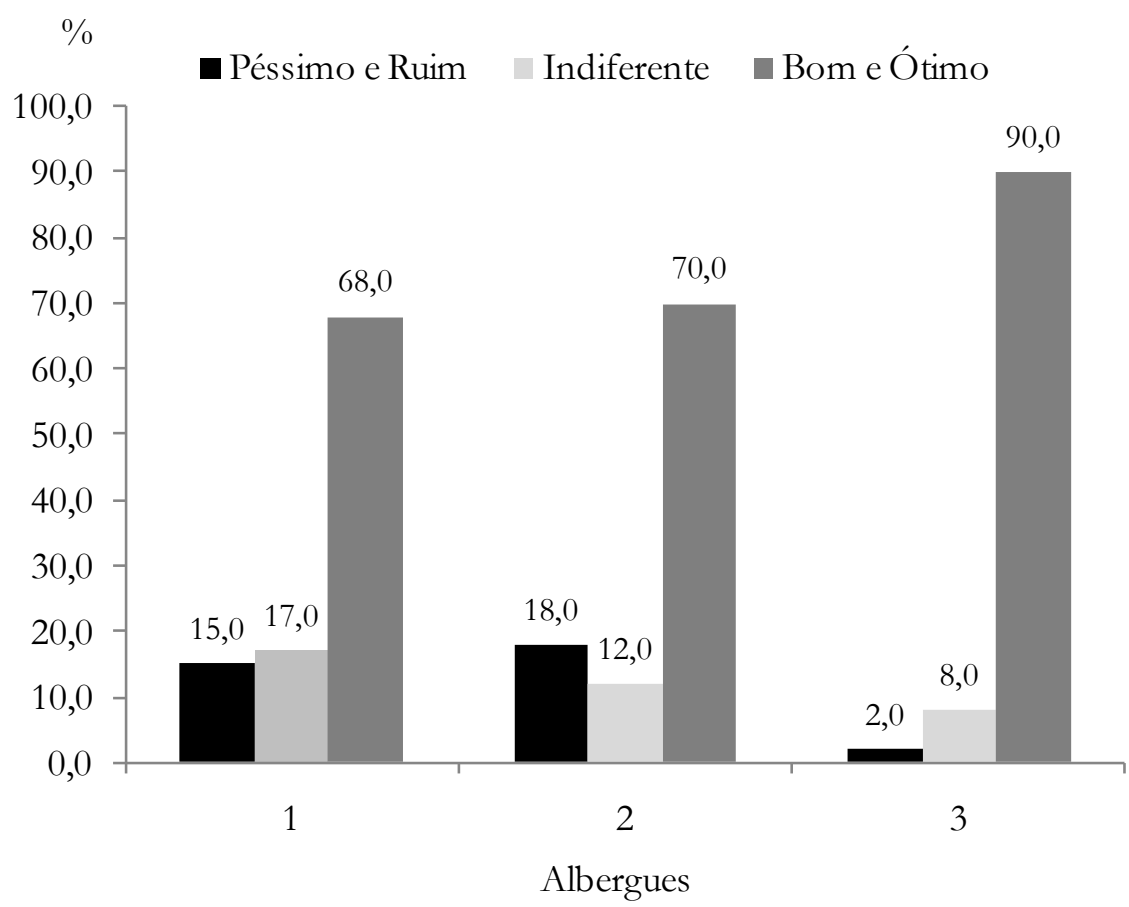

Figura 3. Distribuição dos indivíduos segundo avaliação do sabor da refeição por albergue. São Paulo, 2009.

Avaliando os dados em relação à variedade (Figura 4), verifica-se que nas três instituições a categoria "bom e ótimo" é predominante, representando, $67 \%, 58 \%$ e $82 \%$ da amostra nos albergues 1,2 e 3 respectivamente.

$\mathrm{Na}$ Figura 5 os resultados evidenciam que prevalece a boa aceitação global da refeição nas três instituições, com destaque para o percentual (94\%) obtido no albergue 3 .

As análises entre as variáveis estado nutricional e idade em associação com as análises de sabor, variedade e aceitação global das refeições realizadas pelos indivíduos, não foram estatisticamente significantes.

\section{DISCUSSÃO}

Em 2003 a Fundação Instituto de Pesquisas Econômicas (FIPE), por meio de contrato com a prefeitura de São Paulo, realizou contagem da população de rua, registrando 10.394 pessoas nesta situação. Destas, 6.186 foram localizadas nas ruas e $4.208 \mathrm{em}$ albergues. Em sua maioria são do sexo masculino (84\%), não branco (64\%), concentrando-se no intervalo de 41 a 55 anos de idade (35\%) ${ }^{[13]}$.

Avaliando-se a prevalência de doenças crônicas e seus fatores de risco, na presente pesquisa a proporção de indivíduos que apresentaram sobrepeso, obesidade e hipertensão foi semelhante ao estudo feito por Ferreira [14], em Maceió, com moradoras de uma área livre, a maioria sem alfabetização (55\%), desempregadas ou em trabalhos informais e com renda média mensal de 120 reais. O referido estudo mostrou que $36 \%$ da população apresentaram sobrepeso ou obesidade, além de 14,8\% da amostra ser hipertensa, o que encontra concordância com as tendências evidenciadas desde a Pesquisa Nacional sobre Saúde e Nutrição, de 1989, de acréscimo nas proporções de sobrepeso e obesidade. A prevalência de excesso de peso da população estudada (Figura 1) também foi semelhante à encontrada (40\%) na Pesquisa de Orçamento Familiar (POF), de 2002-2003 [15].

Quando comparados aos indivíduos com peso normal, aqueles com sobrepeso possuem maior risco de desenvolver hipertensão arterial, condições que favorecem o desenvolvimento de doenças cardiovasculares $[16]$. 
Moradores de rua e alimentação em albergues. Santos et al.

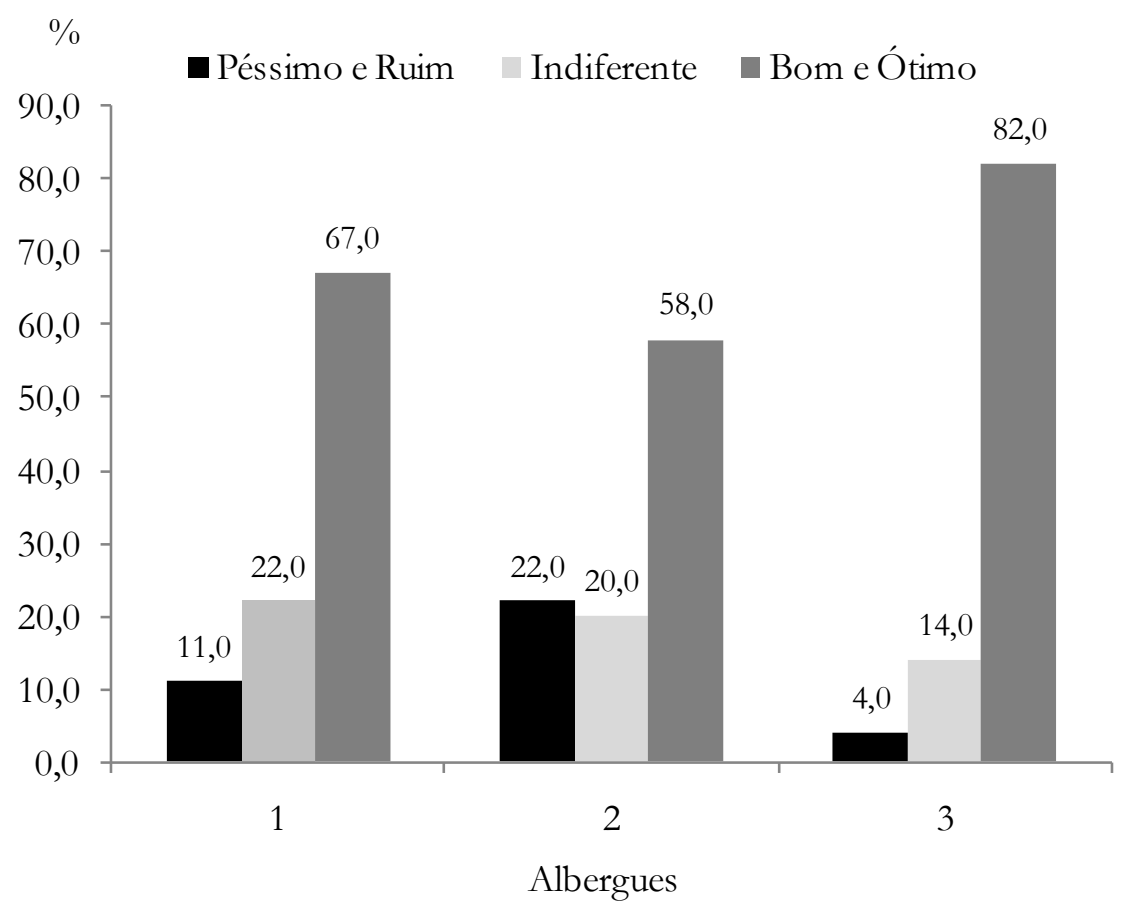

Figura 4. Distribuição dos indivíduos segundo avaliação da variedade da refeição por albergue. São Paulo, 2009.

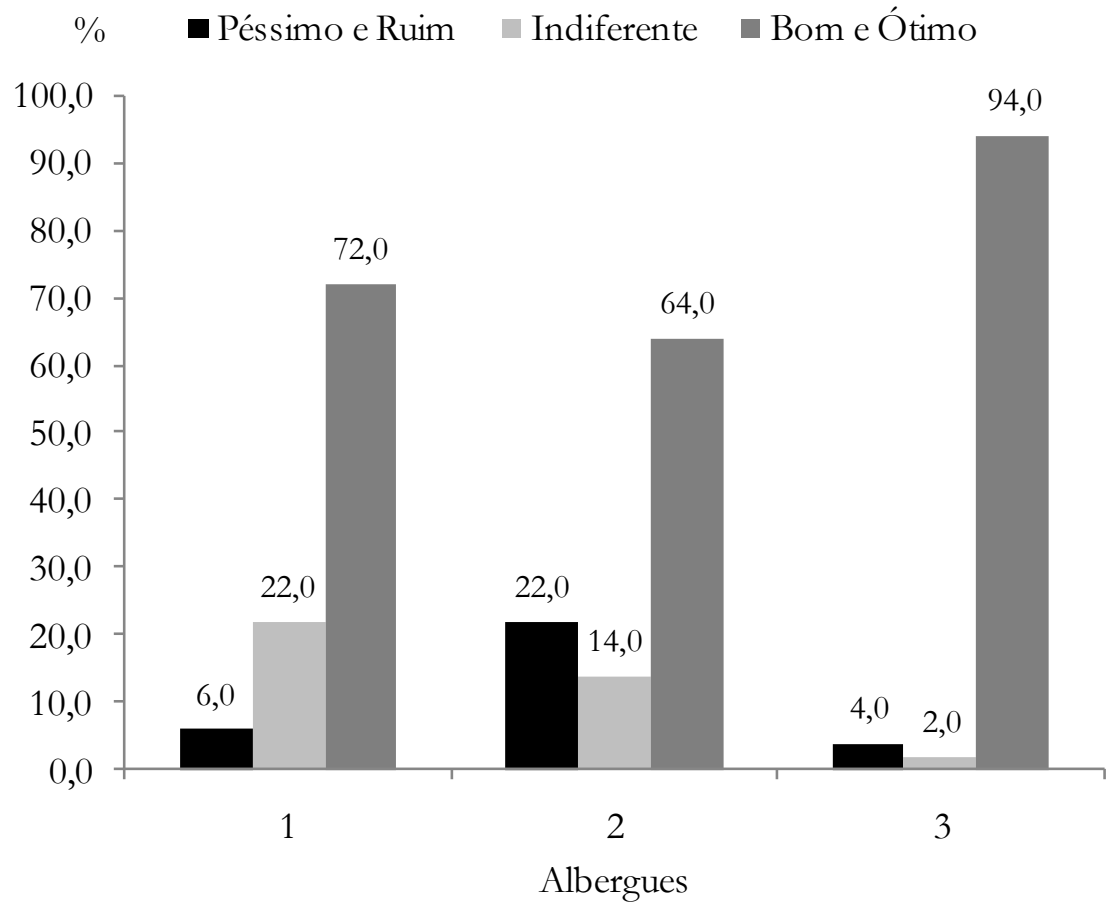

Figura 5. Distribuição dos indivíduos segundo avaliação da aceitação global da refeição por albergue. São Paulo, 2009. 
Oliveira et al. [17] em estudo com adultos da cidade de Salvador (BA), constataram, em análise univariada processada para os homens, que as prevalências tanto do excesso de peso quanto da gordura abdominal eram mais elevadas nas idades entre 30 e 39, e entre 50 e 59 anos, quando comparada com a faixa etária de 20 a 29 anos. Dentre as morbidades referidas, com diagnóstico médico, a hipertensão arterial se associou positivamente com os dois indicadores avaliados. A realização de três ou menos refeições ao dia elevou a prevalência do excesso de peso e da concentração de gordura abdominal, quando comparada com a prevalência destes eventos entre aqueles que realizavam mais de três refeições ao dia. No presente estudo não foi verificado o número de refeições realizadas pelos participantes, no entanto, o conhecimento do número ideal de refeições esteve relacionado a um melhor estado nutricional.

$\mathrm{Na}$ Pesquisa Nacional sobre a População em Situação de Rua, realizada pelo Ministério do Desenvolvimento Social e Combate à Fome, entre os problemas de saúde mais citados destacam-se: hipertensão $(10,1 \%)$, problema psiquiátrico/mental $(6,1 \%), \quad$ HIV/AIDS $(5,1 \%)$ e problemas de visão/cegueira $(4,6 \%)^{[18]}$.

No presente estudo, destacaram-se como patologias mais frequentes (Figura 2): hipertensão (8\%), seguida de hepatite $(2,5 \%)$ e gastrite $(2 \%)$. A dependência química (álcool e drogas) atingiu 1,5\% dos indivíduos, enquanto que problemas visuais e/ou deficiência visual, apenas $1 \%$ da amostra.

O uso abusivo de álcool constitui um grave problema de Saúde Pública. A OMS ${ }^{[19]}$ avalia que o uso problemático de álcool impõe às sociedades uma carga considerável de agravos indesejáveis e altamente dispendiosos. Em um estudo brasileiro multicêntrico de morbidade psiquiátrica em áreas urbanas, o abuso e a dependência de álcool alcançaram prevalência global de até $9 \%$, acometendo principalmente homens [20]. O álcool e as drogas fazem parte da realidade das ruas como alternativa para minimizar a fome e o frio, ou como elemento de socialização. No presente estudo, a dependência química, bem como a presença de outras doenças foi autorreferida, e talvez por isso a proporção de $1,5 \%$ encontrada na pesquisa possa estar subestimada.

No que se refere à composição dos cardápios, Cantelli et al. [21] em estudo qualitativo de cardápios oferecidos em instituições sociais para crianças, verificaram que os cardápios classificados como inadequados para o almoço apresentavam ausência de grupos alimentares, tais como: frutas (43,8\%); seguido das hortaliças, carnes e ovos (12,5\%); e cereais, pães, tubérculos e raízes $(6,3 \%)$. No jantar, o maior percentual de ausência foi observado para os grupos das leguminosas $(75,4 \%)$; seguido das hortaliças $(38,5 \%)$; frutas $(35,4 \%)$; cereais, pães, tubérculos e raízes $(30,8 \%)$ e carnes e ovos $(18,5 \%)$.

Foi verificado no almoço ofertado pelas três instituições (Quadro), a presença de alimentos do grupo das leguminosas, hortaliças, cereais, pães, tubérculos e raízes, e carnes e ovos. A presença de alimentos do grupo das frutas foi verificada durante dois dias, em duas instituições apenas (albergues 1 e 3). Em todos os albergues o prato básico oferecido no almoço era o arroz e o feijão, sendo considerado, do ponto de vista nutricional, como uma adequada combinação de aminoácidos que o organismo não é capaz de produzir.

O jantar era oferecido por duas instituições, sendo constatada a presença de alimentos do grupo das frutas apenas em um dia, somente no albergue 1. Observou-se que no café da manhã do albergue 3 e no lanche da tarde do albergue 2, todos os dias foram oferecidos leite com café e pão com manteiga (no albergue 3) e suco e bolacha de água e sal (albergue 2), caracterizando uma certa monotonia em sua composição.

Por meio da análise da Figura 5, observa-se uma boa aceitação global em relação à alimentação. Nota-se, no entanto, que a instituição com melhor infraestrutura apresentou o segundo menor índice de aceitação global (Albergue 1, com aceitação igual a $72 \%$ ). É preciso ressaltar também que houve diferenças estatisticamente significativas na aceitação das refeições pelos indivíduos, de acordo com os albergues: enquanto $\mathrm{O}$ percentual de rejeição (categorias "péssimo" e "ruim") totalizou 4\% no albergue 3, no albergue 2 essa proporção alcançou 22\%. O critério adotado pelos gestores do Programa Nacional de Alimentação Escolar - PNAE (caracterizado como um programa público, que distribui gratuitamente refeições aos escolares - crianças e jovens) para avaliar a aceitabilidade das refeições, por meio da escala hedônica, é de 85\%. Embora existam diferenças entre a distribuição das refeições em albergues e pelo PNAE (como por exemplo, o público alvo), se utilizássemos o critério adotado pelo PNAE como parâmetro para comparação, apenas o albergue 3 obteria um resultado adequado ( $94 \%$ das refeições consideradas nas categorias "bom" ou "ótimo") [22]. 
Em um estudo realizado em um restaurante universitário da Universidade Federal da Paraíba (UFPB) que teve como objetivo geral analisar o grau de satisfação dos clientes em relação à alimentação servida, o atributo sabor foi avaliado como "ótimo" ou "bom" por 35\% dos entrevistados, "regular" por 39\% e "ruim" ou "péssimo" por 26\%. Convém salientar que a soma dos percentuais entre "péssimo" e "regular" é de $65 \%$, revelando insatisfação em relação ao sabor dos alimentos ${ }^{[14]}$. $\mathrm{Na}$ presente pesquisa, cerca de $30 \%$ dos indivíduos nos albergues 1 e 2, e 10\% no albergue 3, mostraram-se insatisfeitos com o sabor da refeição, indicando as categorias "péssimo", "ruim" ou "indiferente".

Ainda tendo por base o estudo realizado na UFPB [14], o atributo variedade foi avaliado como "ótimo" ou "bom" por 14\% da amostra, alcançando uma proporção menor de aprovação do que a observada entre os albergues (Figura 4).

Com base na análise dos aspectos sensoriais, destaca-se que no albergue 3 , que apresenta a menor infraestrutura e não conta com o profissional nutricionista, foram obtidos resultados mais satisfatórios em todos os subitens analisados (sabor, variedade e aceitação global da refeição). Esse dado pode ser explicado, entre outros fatores, pelo fato de que este albergue atende uma população mais rotativa do que o albergue 1, no qual os frequentadores eram constituídos por aqueles que faziam cursos ou trabalhavam na instituição, mantendo assim um vínculo maior com a mesma. Por outro lado, esta explicação não justifica os resultados encontrados no albergue 2 , que também possui uma clientela mais rotativa.

\section{CONCLUSÃO}

O presente estudo, de natureza exploratória, traçou um retrato pontual de três albergues do município de São Paulo, sem apresentar, no entanto uma amostra representativa da realidade de todos os albergues da cidade.

As condições de saúde e o estado nutricional apresentados pelos frequentadores de albergues refletem em boa parte a atual situação (elevadas prevalências de excesso de peso e de doenças associadas) verificada para a população brasileira, inclusive entre as classes sociais menos abastadas.

As condições em relação à infraestrutura necessária para a elaboração de refeições e à presença do profissional nutricionista diferiram consideravelmente entre os albergues. No entanto, aquele que contava com melhor infraestrutura e equipe de nutricionistas não obteve a melhor avaliação, quanto aos aspectos sensoriais da alimentação distribuída, na opinião dos frequentadores. São necessários estudos que identifiquem os determinantes da aceitação das refeições distribuídas nos albergues.

Por lidar com uma temática ainda pouco presente na literatura científica, o estudo adquiriu o caráter inicial de desvendar uma determinada realidade, procurando dela extrair conteúdos que permitam desdobramentos em pesquisas posteriores.

\section{REFERÊNCIAS}

[1] Dias CJM. População de rua. São Paulo: Hucitec; 1994.

[2] Vieira MAC, Bezerra EMR, Rosa CMM. População de rua. Quem é, como vive, como é vista. São Paulo: Hucitec; 1992.

[3] Glasser I. Homelessness in global perspective. New York: G.K. Hall \& Co; 1994.

[4] Rosa CMM. População de rua: Brasil e Canadá. São Paulo: Hucitec; 1995.

[5] Souza H. Ação e reação contra a miséria. Jornal do Brasil. 1999 [acesso em 20 março 2009]. Disponível em: http://www.ibase.org.br/paginas/acm.html

[6] São Paulo. Decreto no 40.232, de 2 de Janeiro de 2001. Regulamenta a Lei no 12.316, de 16 de abril de 1997, que dispõe sobre a obrigatoriedade do Poder Público Municipal a prestar atendimento à população de rua da Cidade de São Paulo, e dá outras providências [acesso em 20 março 2009]. Disponível em: http://www.prefeitura.sp.gov.br/cidade/secretarias/negocio s juridicos/cadastro de leis/index.php? $\mathrm{p}=325$

[7] Conselho Nacional de Segurança Alimentar e Nutricional. Documento de Referência da II Conferência Nacional de SAN; 2004.

[8] Conselho Nacional de Segurança Alimentar e Nutricional. Documento de Referência da III Conferência Nacional de SAN; 2007.

[9] Fernandes OS, Bernardo CO, Campos RMMB, Vasconcelos FAG. Avaliação do efeito da educação nutricional na prevalência de sobrepeso/obesidade e no consumo alimentar de escolares do ensino fundamental. J Pediatr. 2009;85(4):315-321.

[10] World Health Organization/Food and Agricultural Organization. Diet, nutrition and the prevention of chronic diseases. Geneva: World Health Organization; 2003. (Technical Report Series, 916). 
[11] Brasil. Ministério da Saúde. Secretaria de Atenção à Saúde. Coordenação-Geral da Política de Alimentação e Nutrição. Guia alimentar para a população brasileira: promovendo a alimentação saudável. Brasilia: Ministério da Saúde; 2005. 236p. (Série A. Normas e Manuais Técnicos).

[12] Stata Corporation. Stata Statistical [Software: version 10]. Texas: Stata Corporation; 2007.

[13] Fundação Instituto de Pesquisas Econômicas (FIPE). Censo dos moradores de rua. São Paulo: FIPE; 2003.

[14] Ferreira HS, Florêncio TMTM, Fragoso MAC, Melo FP, Silva TG. Hipertensão, obesidade abdominal e baixa estatura: aspectos da transição nutricional em uma população favelada. Rev Nutr. 2005;18(2):209-218.

[15] Instituto Brasileiro de Geografia e Estatística [homepage]. Pesquisa de Orçamentos Familiares - POF 2002-2003. Análise da disponibilidade domiciliar de alimentos e do estado nutricional no Brasil [acesso em 01 nov 2010]. Disponível em: http://www.ibge.gov.br

[16] Carneiro G, Faria NA, Filho FFR, Guimarães A, Lerario D, Ferreira SRG, et al. Influência da distribuição da gordura corporal sobre a prevalência de hipertensão arterial e outros fatores de risco cardiovascular em indivíduos obesos. Rev Assoc Med Bras. 2003;49(3):306-311.

[17] Oliveira LPM, Assis AMO, Silva MCM, Santana MLP, Santos NS, Pinheiro SMC, et al. Fatores associados a excesso de peso e concentração de gordura abdominal em adultos na cidade de Salvador, Bahia, Brasil. Cad Saude Publica. 2009;25(3):570-582.

[18] Brasil. Ministério do Desenvolvimento Social e Combate à Fome. Secretaria de avaliação e gestão da informação. Pesquisa Nacional sobre a População em Situação de Rua. Brasilia: Ministério do Desenvolvimento Social e Combate à Fome; 2008 [acesso em 30 out 2010]. Disponível em: http:/ /www.mds.gov.br

[19] Organização Mundial da Saúde. O relatório mundial da saúde: saúde mental: nova concepção, nova esperança. Genebra; 2001.

[20] Almeida FN, Mari JJ, Coutinho E, França JF, Fernandes JG, Andreoli SB, et al. Estudo multicêntrico de morbidade psiquiátrica em áreas urbanas brasileiras (Brasília, São Paulo, Porto Alegre). Rev Bras Psiquiatr. 1992;14:93-104.

[21] Cantelli AC, Lisboa M, Romano R, Prozzi S, Martinez S. Análise qualitativa de cardápios planejados para equipamentos sociais mantidos por uma organização social na cidade de São Paulo. Mundo da Saúde. 2009;33(3):303309.

[22] Brasil. Ministério da Educação. Fundo Nacional de Desenvolvimento da Educação. Resolução FNDE no 38, de 16 de julho de 2009. Dispõe sobre o atendimento da alimentação escolar aos alunos da educação básica no Programa Nacional de Alimentação Escolar (PNAE) [acesso em 25 out 2010]. Disponível em: http://www.fnde.gov.br/index.php/legis-resolucoes 